\title{
FUTURE-ORIENTED PGE-PRODUCT GENERATION ENGINEERING: AN ATTEMPT TO INCREASE THE FUTURE USER ACCEPTANCE THROUGH FORESIGHT IN PRODUCT ENGINEERING USING THE EXAMPLE OF THE IPHONE USER INTERFACE
}

\author{
Marthaler, Florian (1); Stahl, Sven (1); Siebe, Andreas (2); Bursac, Nikola (3); Spadinger, Markus \\ (1); Albers, Albert (1) \\ 1: Karlsruhe Institute of Technology, Institut für Produktentwicklung, Karlsruhe; 2: ScMI - Scenario \\ Management International AG, Paderborn; 3: TRUMPF Werkzeugmaschinen $\mathrm{GmbH}+\mathrm{Co}$. KG, \\ Ditzingen
}

\begin{abstract}
During the process of product engineering, decisions with uncertain consequences have to be made about future development (Albers et al., 2017a). Customer, user and vendor requirements that are already known and those who are relevant for the future have to be recognized and transferred into consistent projects. Classical approaches like customer surveys or market analyses are only partially useful for anticipating or validating future product requirements since they rather evaluate todays situation. Methods of foresight are preferably applied to make decisions under circumstances of uncertainty and to generate future knowledge. The following work treats thus a system that enables the user to deduce future requirements based on trend analyses. The system which was first mentioned in Albers et al. and further developed in Marthaler et al. will serve as the basis. (Albers et al., 2018a; Marthaler et al., 2019). The goal is to present and evaluate a system based on the analysis and identification of trends that allows to identify robust requirements for future product generations and to transfer them into concrete development agreements in the form of a development road map.
\end{abstract}

Keywords: PGE-Product Generation Engineering, Innovation, Design for interfaces, Robust design, Foresight based on trends

Contact:

Marthaler, Florian

Karlsruhe Institute of Technology

Institution of product engineering

Germany

florian.marthaler@kit.edu

Cite this article: Marthaler, F., Stahl, S., Siebe, A., Bursac, N., Spadinger, M., Albers, A. (2019) 'Future-oriented

PGE-product Generation Engineering: An Attempt to Increase the Future User Acceptance through Foresight in Product Engineering Using the Example of the iPhone User Interface', in Proceedings of the 22nd International Conference on Engineering Design (ICED19), Delft, The Netherlands, 5-8 August 2019. DOI:10.1017/dsi.2019.371 


\section{INTRODUCTION AND MOTIVATION}

Trends imply upcoming medium-term or already perceptible changes for the future (Siebe, 2018). On the one hand, trends describe thus current changes of technical solutions, such as the electrification of vehicles for example. But on the other hand, they also depict the changes in the consumer habits of client groups, such as the increasing use of car sharing offers. With the help of trends, it is possible to gain insight for a medium-term time. This insight is relevant for today's concept and the development of systems of objectives of future product generations. In order to improve decision-making under circumstances of uncertainty (Chermack and Lynham, 2002) and to deal in an aware way with chances and risks while prioritizing the extent of development, Albers et al. und Marthaler et al. propose a system which enables the systematic use of foresight in product engineering (Albers et al., 2018a; Marthaler et al., 2019). A structured approach is chosen according to the targeted or authorized scale of the respective parts which have to be newly developed (Marthaler et al., 2019). To put it more precisely, this system supports the process of finding search fields with a high innovation potential and thus the designers with finding effective creative solutions. However, there is currently a lack of a process model and a methodical description of approach which allow the analysis of medium-term periods of use and a medium-scaled desired or authorized degree of novelty on the basis of trends.

\section{THE STATE OF RESEARCH}

\subsection{Descriptive models in product engineering: PGE - product generation engineering}

The classical methods of embodiment design by Pahl et al. distinguish between new design, adaptive design and variation design in product engineering (Pahl et al., 2013). But since it is often not possible to make a concrete differentiation between new, variation or adaptive designs in product engineering projects and new designs are hardly found, the classical descriptive model is ineffective and thus only partially useful for industrial practice. In contrast to that, PGE-Product generation engineering enables the description of all product engineering projects in the way they are found in industrial practice. (Albers et al. 2015) In the PGE-model, product engineering always takes place based on a reference system and its customer-tangible characteristics. Elements of a previous generation as well as from competitors or the research department can serve as a reference (Albers et al., 2018c). These elements can also be represented by subsystems. This way, the iPad can be used as a reference for the development of a new communication interface for a new generation of vehicles (Albers et al., 2018a). The customer-tangible characteristics serve as a solution-oriented description of necessary targets of differentiation without giving a concrete technical solution (Albers et al., 2018b). The goal of every product engineering project is to create an innovative product generation which stands out from previous generations and the products of current competitors because of its sufficient number of differentiating features. These differentiating features are achieved with the help of the respective parts which have to be newly developed. There are three types of variation (principle variation, embodiment variation and carryover variation) in the adaptation of subsystems. The principle variation represents the development of a new solution principle to achieve the determined goal. The embodiment variation on the other hand, depicts a redesigning based on an already existing solution principle. The sum of the principle and the embodiment variation constitutes the degree of novelty of a new product generation. The re-use of existing solutions in a new product generation is known as the carryover variation. (Albers et al., 2015)

\subsection{Systematic foresight in product engineering}

The first cycle of the 3-cycles-model by Gausemeier and Plass includes foresight as one of its three subprocesses (Gausemeier and Plass, 2014). According to time horizon and purpose, the following fundamental methods of foresight are applied: prognoses, trends and scenarios. Prognoses imply statements about future events that are based on observations from the past and theoretically founded, objective methods in a time horizon of up to five years (Wübbenhorst et al., 2018). Trends can be seen as that part of a time series that changes relatively slowly over time but gives the clearest indication of the long-term movements in the series (Harvey, 2016). It is distinguished between mega, macro and micro trends. Mega trends depict global, transformational and long-term transformation processes which influence many future markets sustainably (Singh, 2012). Macro trends help in understanding the development of individual markets, while micro trends characterize very specific developments in 
individual target markets and groups. Trends deliver guiding and qualitative findings about a mediumterm period of five to ten years. The most far-reaching foresight is carried out with the help of scenarios. A scenario does not correspond to a prediction but to a concept of the future which results from conclusive combinations of possible developments of influencing factors (Gausemeier and Plass, 2014). Scenarios provide long-term findings about possible futures with a time horizon of ten to fifteen years. For the first time, Marthaler et al. describe a systematic attempt of integrating foresight and gained findings into intergenerational product engineering (Marthaler et al., 2019). The system comprises seven sub-processes which come after one another and can be carried out in three variations (see figure 1).

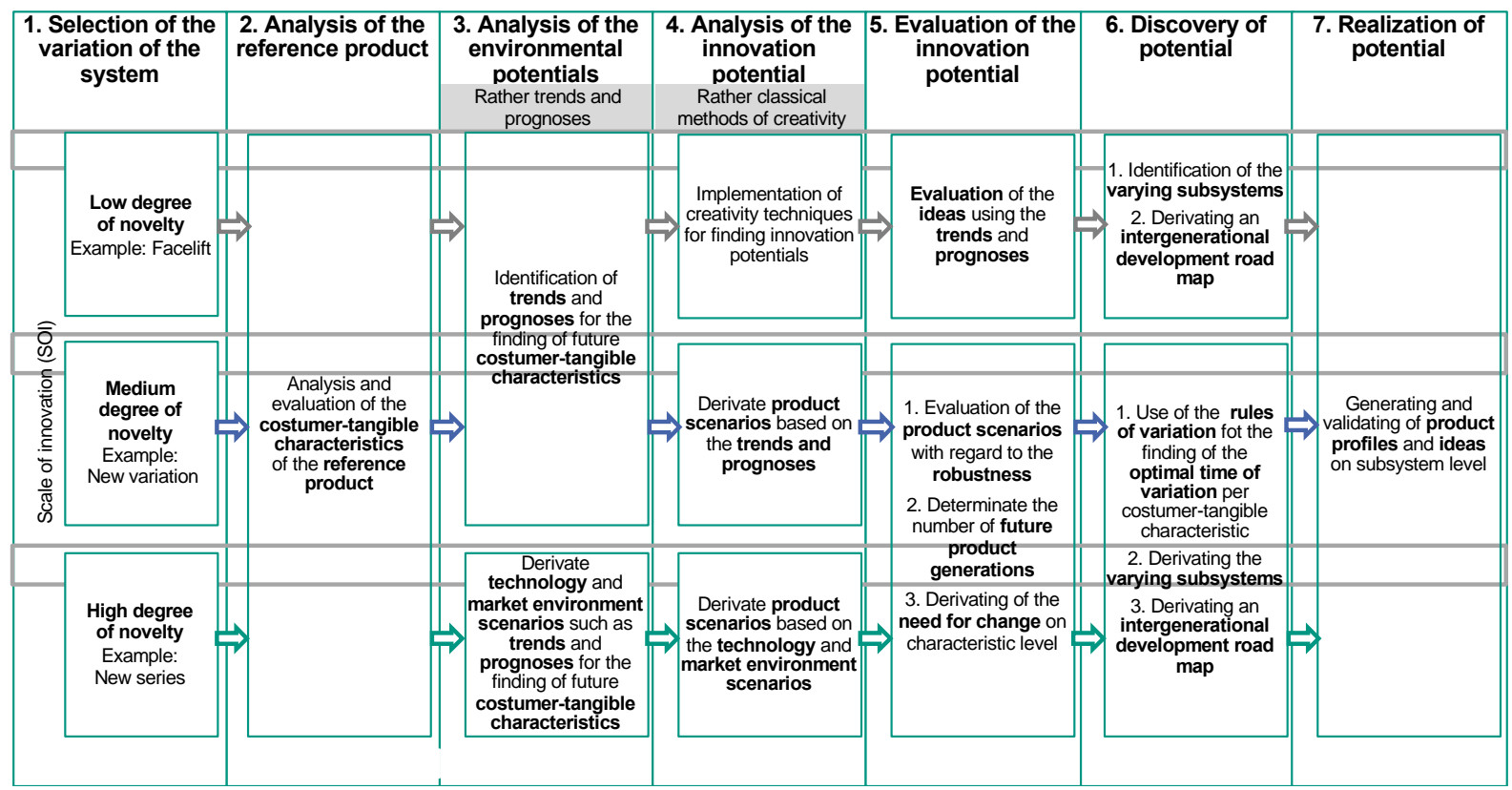

Figure 1: System for deducing intergenerational product road maps according to targeted or authorized degree of novelty (Marthaler et al., 2019)

The selection of the variation occurs in the first of the seven sub-processes depending on the desired or targeted degree of novelty and the examined time horizon. The system distinguishes in three variations between a low, a medium and a high degree of novelty. In the following, generation 911 of the Porsche 911 will be used as a reference to illustrate these three variations. If a facelift of the 911 is going to be developed for a short-term time horizon, e.g. the generation 911 II, the variation with a low targeted degree of novelty is to be consulted. The variation with a medium degree of novelty can be used to develop the successor, in the following called 992. If a completely new type series is going to be developed, e.g. the Porsche Taycan, the variation with a high degree of novelty is to be used.

In the second sub-process, the reference product is identified and analysed. The goal of the process is the identification, analysis and evaluation of today's existing customer-tangible characteristics of the reference product - in this case the 991 II. The evaluation of the fulfilment degree occurs based on a scale with five levels $(--,-, 0,+,++)$. The third sub-process includes the analysis of the environmental potentials. While doing this, future customer-tangible characteristics are to be identified with the help of foresight. For this purpose, context scenarios are developed or trends as well as prognoses are individually identified and investigated according to variation. The next sub-process includes the analysis of the innovation potential. For this, classical methods of creativity (e.g. the persona method) are applied according to variation. The other possibility is to describe product scenarios with the help of today's and future customer-tangible characteristics based on trends and prognoses as well as technology and market environment scenarios. In the fifth sub-process, the evaluation of the innovation potential and the generation of future knowledge occur on the level of the individual customer-tangible characteristics. For this purpose, the key figures - robustness and need for change - are used. Robustness represents the similarities of the product scenarios regarding a customer-tangible characteristic. The range of robustness reaches from 0 to 4 . The need for change of a characteristic describes how much the customer-tangible characteristics of the product scenarios differ from those of the reference product. The range of the need for change reaches from -4 to 4 . The alternative variation depicts the evaluation of ideas with the help of trends and prognoses. In the sixth sub-process, the time of variation of the individual customer-tangible 
characteristics are defined with the help of the rules of variation. (Marthaler et al., 2019) This is executed according to the robustness and the need for change within the framework of finding potential (Albers et al., 2018a). This way, the scale of development is assigned to a specific product generation. The goal of the sub-process is to identify and to prioritize the innovation potential. As an alternative, the subsystems which need to be modified can be identified directly by applying another variation. Afterwards, it is possible to deduce intergenerational development road maps which are based on subsystems. In the last sub-process of the realization of potential, product profiles and ideas on the level of subsystems are generated and validated based on development road maps. (Marthaler et al., 2019)

\subsection{Design as a special characteristic of embodiment}

The design of a product can be described as the quality with regard to its ability of being operated and its usability as well as to its perceptibility and recognizability by the user (Schmid and Maier, 2017). Besides its realization of technical requirements, the design of a product includes tasks about the appearance and about the elicited emotions of the product as a part of the 'user experience' (Khalid and Helander, 2006). Therefore, it is important to integrate perceptible and recognizable characteristics as characteristics of differentiation during a product engineering process. However, the objective evaluation of the product design regarding its aesthetics cannot be formulated because of its high range of subjectivity. Nevertheless, there is the possibility of investigating current design trends to enable an objective evaluation in the product engineering process. Another method is the application of the Aesthetic Measure by Birkhoff. It was formulated in 1933 by the mathematician Georg D. Birkhoff and defines the aesthetics of a system based on the aesthetic measure. The latter is calculated from the quotient of the degree of order $\mathrm{O}$ and the complexity $\mathrm{C}$ of the system. The degree of order results from the product of number and species number of the orders, while the complexity is calculated from the number and species number of the elements. Therefore, Birkhoff defines a product with a high degree of order and low complexity as aesthetic. (Birkhoff, 1933) Since the launch of the iPhone in 2007, a design with few physical control elements, inspired by the simplicity of the Apple design (Shelley, 2015), dominates the design on the smartphone market. According to Birkhoff, the degree of order, and thus the aesthetic measure, was increased by removing the keyboard which lead to the reduce of physical control elements.

\section{RESEARCH NEEDS AND RESEARCH METHOD}

\subsection{Research needs}

This state of research underlines that the existing process models aim especially at individual future product generations. However, the intergenerational investigation based on foresight has not been thoroughly studied yet. For this purpose, there is a lack of a methodical approach for observing successive product generations with a medium-term period of use or a medium desired or authorized degree of novelty. All in all, the following research questions can be deduced:

- How can future customer-tangible characteristics based on a trend analysis be identified within the framework of a medium-term period of use?

- Which systematic approach is needed to enable an aware treatment of chances and risks based on trends?

- Which systematic approach is needed to enable the deduction of development road maps with several successive product generations by trend analyses?

\subsection{Research method}

In order to give an answer to the question how future customer-tangible characteristics are currently deduced on the basis of trends and thus the trend-based development of robust products is enabled, the corresponding literature will be analysed. Based on this method, a systematic approach will be developed and validated based on four interviews with experts within the framework of an exploratory study. The experts mentioned are a designer, an expert of foresight, a development supplier and a method engineer. The approach will also be explained by an example: iPhone 6 - Apple. In the course of applying the example, an online survey about the evaluation of the reference product was held. 48 people in the age of 14 to 59 have participated in the survey. The majority of the persons questioned were between 20 and 22 
years old (45\%). 29 of 48 persons questioned indicated that they possess an iPhone while 16 of them use the model iPhone $6(55 \%)$.

\section{RESULTS}

\subsection{Trend analysis and identification of future customer-tangible characteristics}

In order to identify future customer-tangible characteristics based on trends, a trend analysis to investigate the trends which are relevant for the development context is needed. For this purpose, a system was developed on the basis of the principle of comparison in pairs. It assigns an index to every trend. In conclusion, a ranking is created based on the index. In order to investigate the index, the standardized weighting factors $(\mathrm{nG})$ of the individual mega trends (nGMegatrend) and macro trends (nGMacrotrend) are determined. These are defined by a comparison of trends (see figure 2).

\begin{tabular}{|cc|c|c|c|c|c|c|}
\hline & 1 & 2 & 3 & $\ldots$ & $\mathrm{n}-1$ & $\mathrm{n}$ \\
\hline 1 & Trend 1 & & & & & & \\
\hline 2 & Trend 2 & & & & & & \\
\hline 3 & Trend 3 & & & & & & \\
\hline$\ldots$ & $\ldots$ & & & & & & \\
\hline 5 & Trend n-1 & & & & & & \\
\hline 6 & Trend $\mathrm{n}$ & & & & & & \\
\hline
\end{tabular}

\begin{tabular}{|l}
\hline Legend \\
\hline $2: 0=1$ st trend more important than 2nd trend \\
$1: 1=1$ st trend as important as 2nd trend \\
$0: 2=1$ st trend less important than 2nd trend \\
\hline
\end{tabular}

Figure 2: Comparing trends according to the principle of comparison in pairs to determine the standardized weighting factor

On the basis of the legend, the results in the rows are determined and added up to calculate the absolute weighting factor $(\mathrm{aG})$. Afterwards the maximum weighting factor $(\mathrm{mG})$ is calculated $(\mathrm{mG}=($ $\mathrm{n}-1$ ) $\mathrm{x} 2$ ). In order to determine the standardized weighting factor $(\mathrm{nG})$, the quotient from the absolute and the maximum weighting factor is calculated. This system is both applied on the level of the mega trends and the macro trends. The index $\mathrm{R}$ results from the product of nGMegatrend and nGMacrotrend and assigns a result in the value of $(0,1)$ to every macro trend. This result represents thus the relevance of the macro trends and includes also the relevance of the corresponding mega trends. Figure 3 illustrates an excerpt of derivation of the index $\mathrm{R}$ including the comparison of the mega trends and the macro trends of the mega trend Artificial Intelligence.
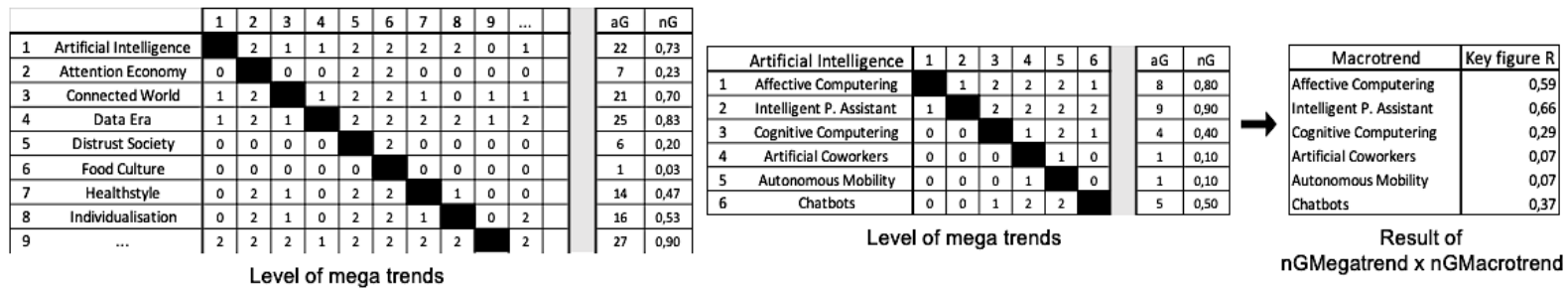

Figure 3: Excerpt of the derivation of the index $R$ for the iPhone 6

In conclusion, a ranking based on the index $\mathrm{R}$ is created and the about 20 most important trends are identified. In the following step, the identified trends are compared to the customer-tangible characteristics. The goal is to carry out an analysis of consistency. The evaluation occurs according to the legend added to figure 5. A strong accentuation represents a positive development of the customertangible characteristics, e.g. the enlargement of the display. In contrast to this, a weak accentuation describes a negative development of the customer-tangible characteristics, such as the loss of data security. Furthermore, it is distinguished between the direct and the indirect influence of trends (directly/indirectly consistent). Based on the results from the analysis of consistency, white spots and irrelevant factors can be pointed out. If only few or no customer-tangible characteristics are addressed by a trend, the results indicate that there is a lack of future relevant customer-tangible characteristics. But if a characteristic is addressed by only few trends, the future relevance of the trend is to be questioned (see figure 4). 


\begin{tabular}{|c|c|c|c|c|c|c|c|c|c|c|c|c|c|c|c|}
\hline $\begin{array}{l}\text { Macro trends/ } \\
\text { Customer-tangible } \\
\text { characteristics }\end{array}$ & 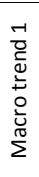 & 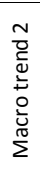 & 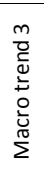 & 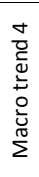 & $\vdots$ & 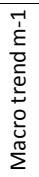 & 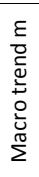 & $\begin{array}{l}\text { Macro trends/ } \\
\text { Customer-tangible } \\
\text { characteristics }\end{array}$ & 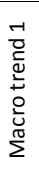 & 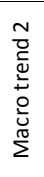 & 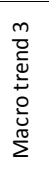 & 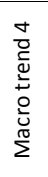 & $\vdots$ & 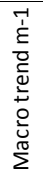 & 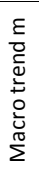 \\
\hline Customer-tangible characteristic 1 & 0 & 0 & 0 & 0 & 0 & 0 & +++ & Customer-tangible characteristic 1 & 0 & 0 & 0 & 0 & 0 & 0 & ++ \\
\hline Customer-tangible characteristic 2 & + & 0 & 0 & 0 & + & 0 & 0 & Customer-tangible characteristic 2 & + & 0 & 0 & 0 & + & 0 & 0 \\
\hline Customer-tangible characteristic 3 & 0 & 0 & 0 & 0 & 0 & 0 & 0 & Customer-tangible characteristic 4 & - & 0 & 0 & - & - & 0 & 0 \\
\hline Customer-tangible characteristic 4 & - & 0 & 0 & - & - & 0 & 0 & $\ldots$ & 0 & 0 & 0 & ++ & 0 & 0 & 0 \\
\hline$\ldots$ & 0 & 0 & 0 & ++ & 0 & 0 & 0 & Customer-tangible characteristic $n-1$ & + & 0 & ++ & 0 & 0 & 0 & 0 \\
\hline Customer-tangible characteristic $n-1$ & + & 0 & ++ & 0 & 0 & 0 & 0 & Customer-tangible characteristic $n$ & 0 & 0 & 0 & + & 0 & ++ & 0 \\
\hline Customer-tangible characteristic $n$ & 0 & 0 & 0 & + & 0 & ++ & 0 & Customer-tangible characteristic $n+1$ & 0 & ++ & + & 0 & 0 & 0 & 0 \\
\hline
\end{tabular}

\begin{tabular}{|l|c|}
\hline $\begin{array}{c}\text { Strong appliance of the characteristic - directly consistent } \\
\text { Strong appliance of the characteristic - indirectly consistent }\end{array}$ & ++ \\
\hline $\begin{array}{c}\text { Characteristic independent } \\
\text { Weak appliance of the characteristic - indirectly consistent }\end{array}$ & 0 \\
\hline Weak appliance of the characteristic - directly consistent & - \\
\hline
\end{tabular}

Figure 4: Comparing the customer-tangible characteristics with the relevant trends from the trend analysis to determine future customer-tangible characteristics

\subsection{A systematic approach to deduce an intergenerational development road map}

On the basis of the system by Albers et al. und Marthaler et al. which was described in the chapter about the state of research, the following passage will explain a systematic approach to deduce an intergenerational development road map based on the example of the iPhone 6 produced by (the company) Apple (Albers et al., 2018a; Marthaler et al., 2019).

\subsubsection{Selection of the variation of the system}

The variation with a medium degree of novelty in a medium-term time horizon is selected. The process is portrayed in figure 1 .

\subsubsection{Analysis of the reference product}

In the second step, the reference product is chosen. Afterwards, the reference product is investigated and evaluated with regard to its customer-tangible characteristics. As described in the chapter about the state of research, the evaluation of the fulfilment degree of the customer-tangible characteristics is carried out with the help of a scale with five levels $(--,-, 0,+,++)$. The evaluation of the reference product's (iPhone 6) customer-tangible characteristics was executed by means of an online survey. Figure 5 represents an excerpt of the survey in the form of a questionnaire.

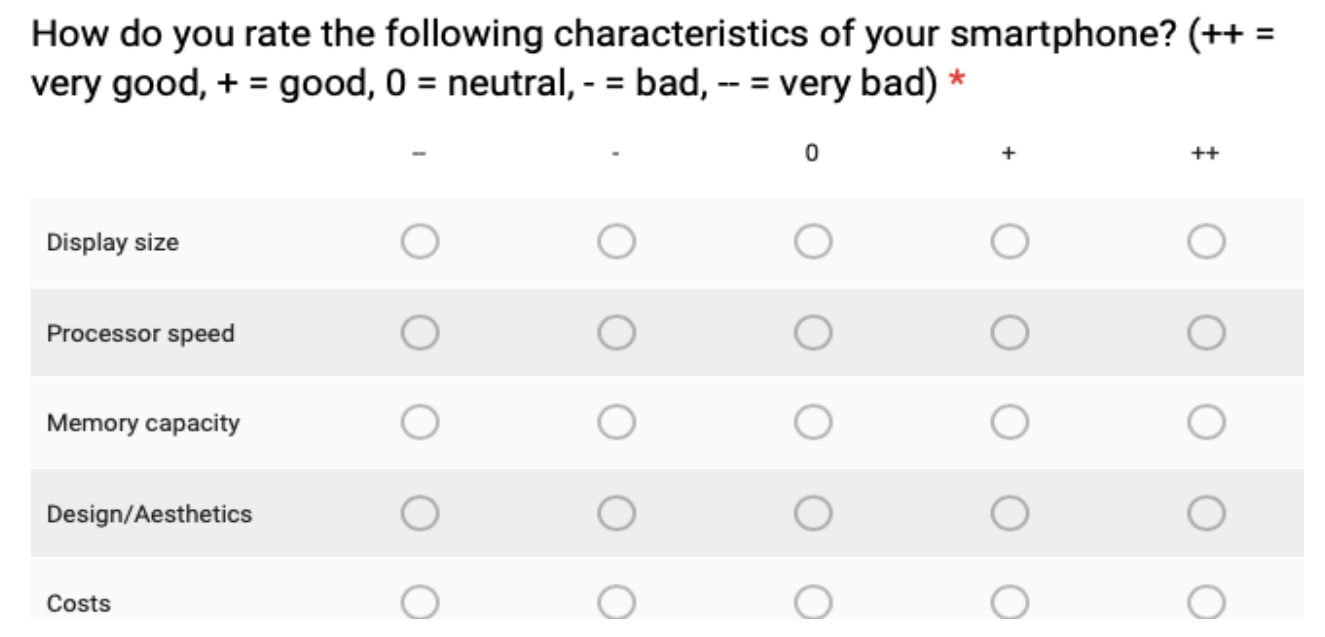

Figure 5: Questionnaire with a Likert scale with five levels to evaluate the relevance of the customer-tangible characteristics of the iPhone 6

The results of the online survey are evaluated with the help of a box plot diagram (see figure 6). 


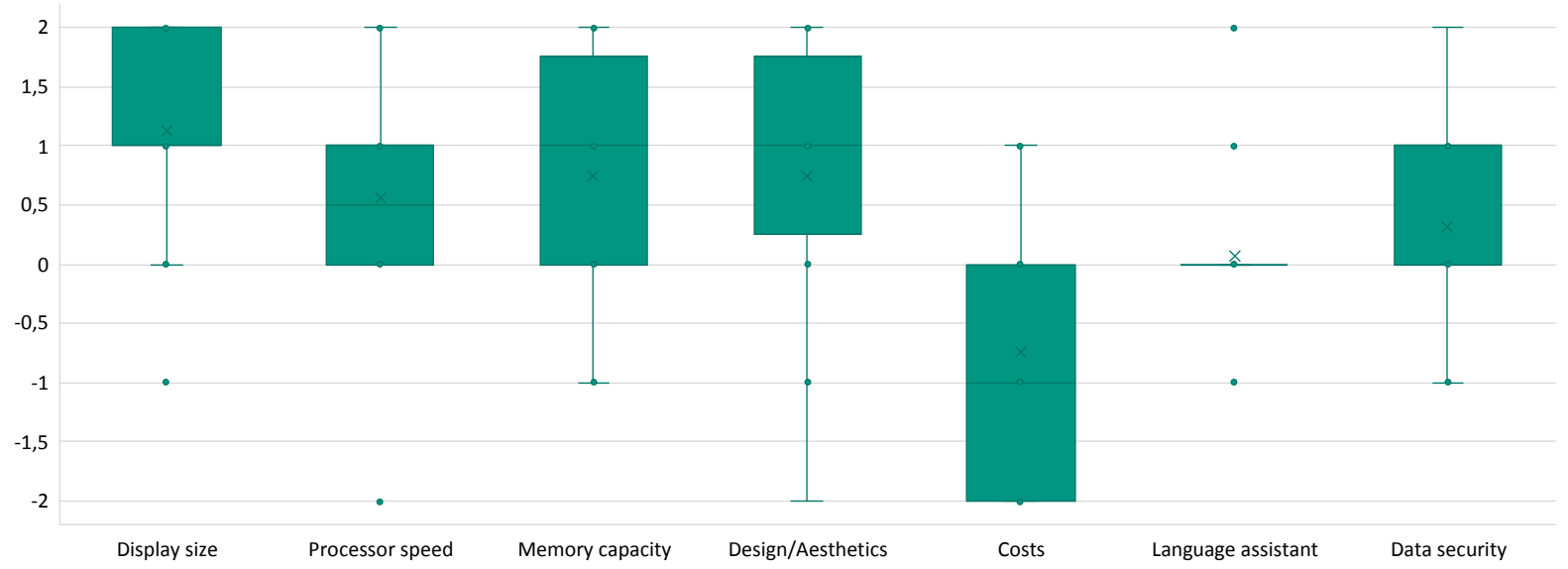

Figure 6: Box plot diagram of the results from the questionnaire (excerpt)

\subsubsection{Analysis of the environmental potential}

In this step, the system described in passage 4.1 will be used to identify future customer-tangible characteristics based on a trend analysis. Based on R, the relevant trends are identified. Figure 7 demonstrates the ranking.

\begin{tabular}{|l|rl|l|}
\hline Macro trend & Key figure R & \\
\hline Augmented \& Mixed Reality & 0,87 & Affective Computering & 0,59 \\
Internet of Things & 0,81 & Circular Economy & 0,51 \\
Waerable Technologies & 0,80 & Energy Harvesting & 0,51 \\
Natural User Interfaces & 0,72 & Brain-Computer Interface & 0,50 \\
Life Sharing & 0,70 & Machine Sensing & 0,50 \\
Intelligent Personal Assistant & 0,66 & Smart Materials & 0,50 \\
Cybersecurity & 0,65 & Smart Data & 0,48 \\
Data Transmission & 0,65 & Purification & 0,47 \\
User Profiling & 0,65 & Customisation & 0,47 \\
Seamless Media & 0,63 & Performance Culture & 0,47 \\
\hline
\end{tabular}

Figure 7: Ranking of the macro trends (Top 20)

In conclusion, the customer-tangible characteristics are revised. This is portrayed in figure 8.

\begin{tabular}{|c|c|c|c|c|c|c|c|}
\hline $\begin{array}{l}\text { Macro trends/ } \\
\text { Customer-tangible } \\
\text { characteristics }\end{array}$ & 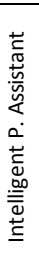 & 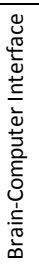 & 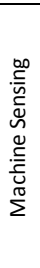 & 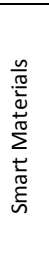 & 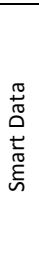 & : & 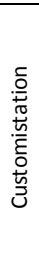 \\
\hline Display size & 0 & 0 & 0 & 0 & 0 & 0 & ++ \\
\hline Resolution & 0 & 0 & 0 & 0 & 0 & 0 & 0 \\
\hline Processor speed & + & 0 & 0 & 0 & + & 0 & 0 \\
\hline Memory capacity & 0 & 0 & 0 & 0 & 0 & 0 & 0 \\
\hline \multirow{3}{*}{$\begin{array}{c}\text { Design/Aesthetics } \\
\ldots \\
\text { Degree of individualization }\end{array}$} & 0 & 0 & 0 & + & 0 & 0 & + \\
\hline & 0 & + & 0 & 0 & 0 & 0 & 0 \\
\hline & + & 0 & 0 & 0 & 0 & 0 & ++ \\
\hline
\end{tabular}

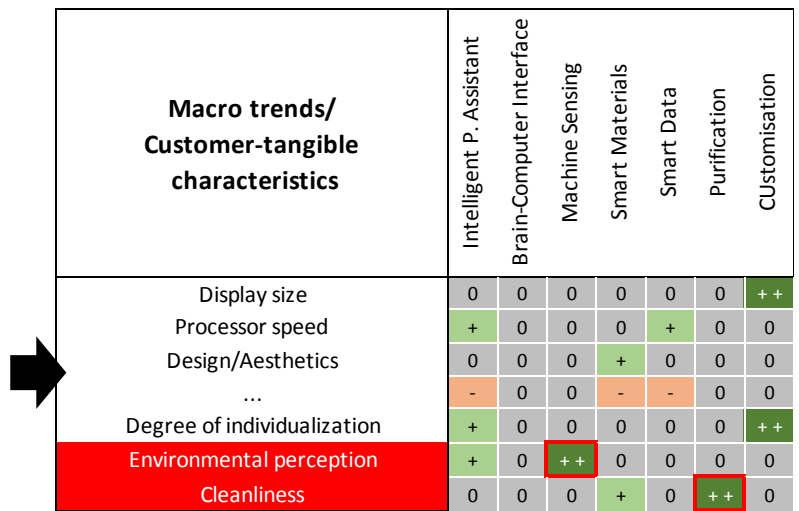

Figure 8: Comparing the customer-tangible characteristics with the relevant trends from the trend analysis to revise the customer-tangible characteristics

The consistency analysis underlines the irrelevance of the customer-tangible characteristics 'Resolution' and 'Memory capacity'. It is striking that these characteristics - despite their constant improvement - do not play a relevant role according to the trend analysis. Furthermore, the lacking dependence of the customer-tangible characteristics on the macro trends 'Machine Sensing' and 'Purification' depicts the incompleteness of the customer-tangible characteristics. This gap can be filled by adding 'Environmental perception' and 'Cleanliness'. 


\subsubsection{Analysis of the innovation potential}

With the help of the morphological analysis (see figure 9), various product scenarios are brought out. The revised customer-tangible characteristics serve as parameters (first column). In the first row, possible accentuations (comparison passage 4.2.2) are listed. Umbrella terms are chosen. Based on the terms, consistent product scenarios are deduced from the customer-tangible characteristics and their accentuations.

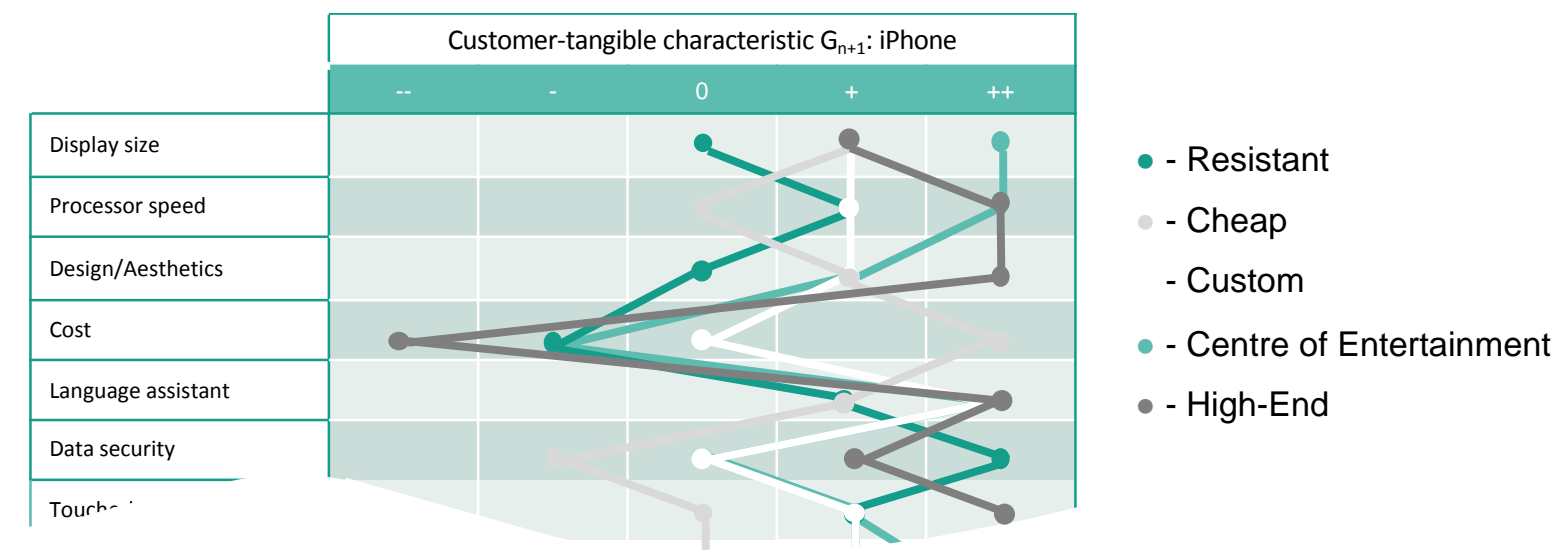

Figure 9: Morphological analysis

The first product scenario called 'Resistant' is characterized by a very strong accentuation of the robustness. The use of 'Smart Materials' is supposed to allow the installation of a self-healing display. The product scenario 'Cheap' represents an inexpensive variation. The third product scenario 'Custom' includes a very strong accentuation of the degree of individualization. This way, elements such as the display, the camera as well as the capacity and the charging process of the battery can be varied individually. In contrast to this, the scenario 'Centre of entertainment' is characterized by a very strong accentuation of the display size and the sound quality. The surround mode enables a cinema-like experience. The last product scenario 'High-End' is characterized by a very strong accentuation of the processor speed and the data security. The design is based on the unity of form. Figure 10 shows sketches and provides more detailed information about the product scenarios.

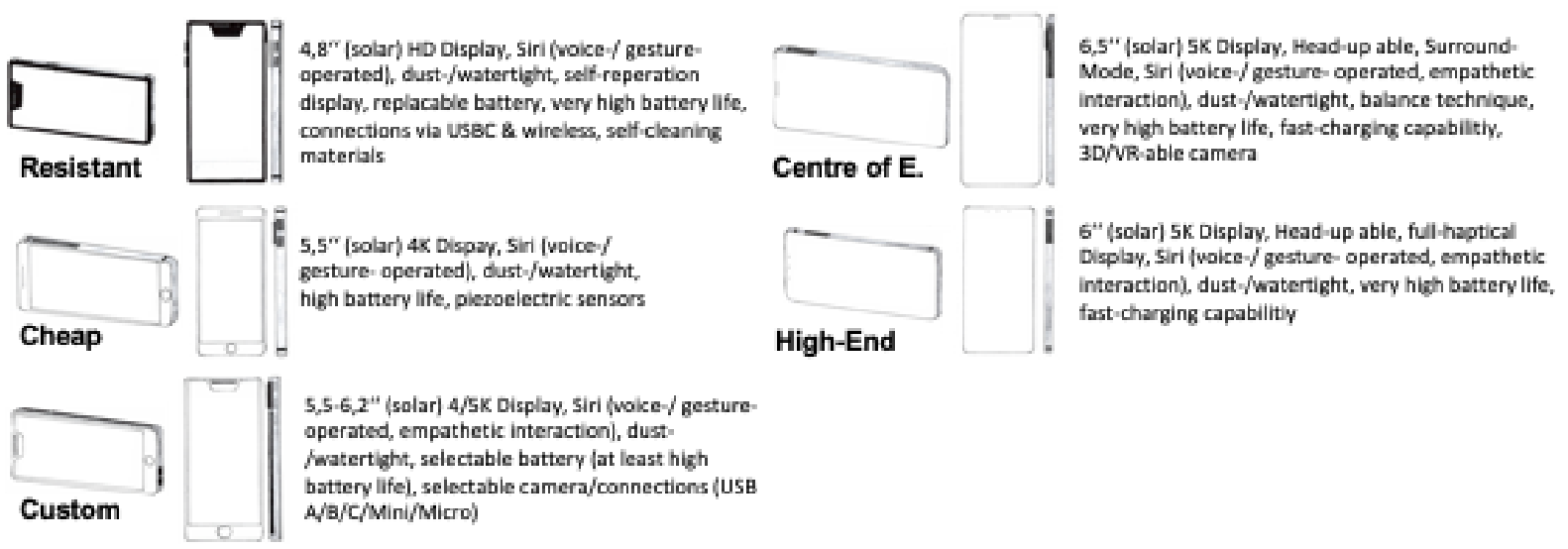

Figure 10: Information concerning the product scenarios

\subsubsection{Evaluation of the innovation potential}

In order to evaluate the potential, two key figures - the need for change and robustness - are introduced and determined (Marthaler et al., 2019). Based on the robustness, the optimal number of product scenarios is found out: level of robustness $>3$. By combining the product scenarios 'Cheap', 'Custom', 'Centre of Entertainment' and 'High-End', the number of product scenarios is reduced from five to three. 


\subsubsection{Discovery of potential}

In the course of finding potential, the rules of variation explained in Albers et al. are applied first to deduce the time of variation from them (Albers et al., 2018a). This way, early (up to 5 years), middleterm (5 to 10 years) and late (10 to 15 years) times of variation are calculated (see figure 11).

\begin{tabular}{|c|c|c|c|c|c|c|c|c|}
\hline $\begin{array}{l}\text { Customer-tangible } \\
\text { characteristic }\end{array}$ & $\begin{array}{c}\begin{array}{c}\text { Reference } \\
\text { product }\end{array} \\
\end{array}$ & \begin{tabular}{|c|}
$\begin{array}{c}\text { Need for } \\
\text { change product } \\
\text { scenarios }\end{array}$ \\
\end{tabular} & $\begin{array}{l}\text { Need for } \\
\text { change macro } \\
\text { trends }\end{array}$ & $\begin{array}{c}\text { Future- } \\
\text { robustness }\end{array}$ & 5 years & $5-10$ years & \multirow{5}{*}{$\begin{array}{l}\text { End } \\
\\
\text { time- } \\
\text { scale }\end{array}$} & $10-15$ years \\
\hline Display size & 1 & 0,5 & 0,5 & \begin{tabular}{l|l}
1 \\
\end{tabular} & & medium-term variation & & \\
\hline Processor speed & 1 & 1,0 & 0,2 & 2 & short-term variation & & & \\
\hline Design/Aesthetics & 1 & 0,5 & 0,0 & 2 & & no variation & & \\
\hline Costs & -1 & $-0,5$ & $-0,1$ & 0 & & medium-term variation & & \\
\hline Language assistant & 0 & 1,5 & 1,4 & 3 & short-term variation & & \multirow[t]{3}{*}{ trends } & \\
\hline Data security & 1 & 0,0 & $-1,0$ & 1 & & & & long-term variation \\
\hline Tount s. & & & $n a$ & 2 & & no variation & & \\
\hline
\end{tabular}

Figure 11: Depiction of the time of variation in dependence on the need for change of scenarios, trends and robustness

However, statements about a late time of variation have to be verified at a later point in time since they are only based on trends - an instrument of middle-term foresight. In the next step, the interactions between the customer-tangible characteristics and the product features have to be investigated. Afterwards, the product features are transferred into the subsystems. Based on the customer-tangible characteristics, the times of variation and the subsystems, an intergenerational development road map based on subsystems is created. Figure 12 depicts the development road map of the example.

\begin{tabular}{|c|c|c|c|c|c|c|c|c|}
\hline $\begin{array}{l}\text { Customer-tangible } \\
\text { characteristic }\end{array}$ & $\begin{array}{c}\text { Reference } \\
\text { product }\end{array}$ & $\begin{array}{c}\text { Need for } \\
\text { change product } \\
\text { scenarios }\end{array}$ & $\begin{array}{c}\text { Need for } \\
\text { change macro } \\
\text { trends }\end{array}$ & $\begin{array}{c}\text { Future- } \\
\text { robustness }\end{array}$ & 5 years & $5-10$ years & \multirow{9}{*}{$\begin{array}{l}\text { End } \\
\text { time- } \\
\text { scale } \\
\text { trends }\end{array}$} & $10-15$ years \\
\hline Display size & 1 & 0,5 & 0,5 & 1 & & $\begin{array}{l}\text { adapt display size/ } \\
\text { Display/Touchscreen }\end{array}$ & & \\
\hline Processor speed & 1 & 1,0 & 0,2 & 2 & $\begin{array}{l}\text { increase processor speed/ } \\
\text { Processorchip }\end{array}$ & & & \\
\hline Design/Aesthetics & 1 & 0,5 & 0,0 & 2 & & no variation & & \\
\hline Costs & -1 & $-0,5$ & $-0,1$ & 0 & & $\begin{array}{c}\text { reduce costs/ } \\
\text { Case/Battery/Display }\end{array}$ & & \\
\hline Language assistant & 0 & 1,5 & 1,4 & 3 & $\begin{array}{l}\text { expand language assistant// } \\
\text { Software/Sensors }\end{array}$ & & & \\
\hline Data security & 1 & 0,0 & $-1,0$ & 1 & & & & Data security/Software \\
\hline \multirow[t]{2}{*}{ Touch detection } & 1 & 0,5 & 0,5 & 2 & & novariation & & \\
\hline & & & & 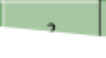 & increase audio quality/ & & & \\
\hline
\end{tabular}

Figure 12: Subsystem-specific, intergenerational development road map in dependence on the need for change of scenarios, trends and robustness

\subsubsection{Realization of potential}

In the last step, the subsystem-specific product profiles are defined on the basis of the development road map. The product profiles serve as the basis of other product engineering processes. This way, product developers receive more specific and manageable development agreements.

\section{INTERPRETATION AND PROSPECTS}

The investigation based on the exploratory study and the four interviews with the experts demonstrates that trends are useful for determining future customer-tangible characteristics. The limitation of the time horizon to a middle-term as well as the limitation of the degree of novelty to a low degree are seen as necessary requirements for the application of trends. A systematic approach is created for this purpose. The identification of all current trends and the generation of a summary present difficulties. In the course of this work, a trend analysis is executed based on the results of the company TRENDONE. In order to identify the most important trends of the development context, a system based on the principle of the comparison in pairs is formulated. The evaluation of the relevance of the trends among each other is carried out by subjective opinion and thus allows space for secondary verifications. Furthermore, the selection of the number of the most important trends has occurred with the help of a number determined beforehand. Based on a more objective evaluation within the comparison in pairs, the determination of a number based on a lower level for the value of the index $\mathrm{R}$ is another possible option. This approach enables a more specific selection of the relevant trends. In the following, the scope of the system introduced should be verified and expanded if possible. The 
application of the system is currently limited to a $\mathrm{B} 2 \mathrm{C}$ project. However, it is also possible to use it in a B2B context. An example would be the revision of the workplace of a bus driver of the current bus generation of the Karlsruher Verkehrsverbund KVV.

\section{REFERENCES}

Albers, A., Bursac, N. and Wintergerst, E. (2015), "Product generation development-importance and challenges from a design research perspective", In: New Developments in Mechanics and Mechanical Engineering.

Albers, A., Dumitrescu, R., Marthaler F., Albers, A. A., Kühfuss, D., Strauch, M., Siebe, A. and Bursac, N. (2018a), PGE-Produktgenerationsentwicklung und Zukunftsvorausschau: Eine systematische Betrachtung zur Ermittlung der Zusammenhänge

Albers, A., Heitger, N., Haug, F., Fahl, J., Hirschter, T. and Bursac, N. (2018a) "Supporting Potential Innovation in the Early Phase of PGE - Product Generation Engineering: Structuring the Development of the Initial System of Objectives". R\&D Management Conference 2018, Mailand, Italy.

Albers, A., Rapp, S., Heitger, N., Wattenberg, F. and Bursac, N. (2018b), "Reference Products in PGE - Product Generation Engineering: Analyzing Challenges Based on the System Hierarchy" in Procedia CIRP Vol. 70, pp: 469-474. https://doi.org/10.1016/j.procir.2018.02.046

Beitz, W. (2013), Konstruktionslehre - Methode und Anwendung erfolgreicher Produktentwicklung, Springer, Berlin. https://doi.org/10.1007/978-3-642-29569-0

Birkhoff, G. D. (1933), Aesthetic Measure, Harvard University Press, Cambridge Massachusetts. https://doi.org/10.4159/harvard.9780674734470

Chermack, T. J. and Lynham, S. A. (2002), "Definitions and Outcome Variables of Scenario Planning", Human Resource Development Review, Vol. 1 No. 3, pp. 366-38. https://doi.org/10.1177\%2F1534484302013006

Gausemeier, J. and Plass, C. (2014), Zukunftsorientierte Unternehmensgestaltung - Strategien, Geschäftsprozesse und IT-Systeme für die Produktion von morgen, Hanser, Munich. https://doi.org/10.3139/9783446438422

Harvey, A (2016), Trend Analysis, In Wiley StatsRef: Statistics Reference Online (eds N. Balakrishnan, T. Colton, B. Everitt, W. Piegorsch, F. Ruggeri and J. L. Teugels). http://doi.org/10.1002/9781118445112.stat07817.pub2

Khalid, H. M. and Helander, M. G. (2006), "Customer Emotional Needs in Product Design", Concurrent Engineering, Vol. 14 No. 3, pp. 197-206. https://doi.org/10.1177\%2F1063293X06068387

Marthaler, F., Orsolani Uhlig, E., Siebe, A., Bursca, N. and Albers, A. (2019), Strategische Potentialfindung zur generationsübergreifenden Produktentwicklung mit langfristigem Zeithorizont: Eine qualitative Studie im Live-Lab IP - Integrierte Produktentwicklung; Karlsruhe

Pahl, G. and Beitz, W. (2013), Konstruktionslehre - Methode und Anwendung erfolgreicher Produktentwicklung, Springer, Berlin. http://doi.org/10.1007/978-3-642-29569-0

Schmid, M. and Maier, T. (2017), Technisches Interface Design - Anforderungen, Bewertung und Gestaltung; Springer; Berlin; https://doi.org/10.1007/978-3-662-54948-3

Shelley, C (2015), The nature of simplicity in Apple design, The Design Journal An International Journal for All Aspects of Design, Vol. 18 No. 3, pp. 439-456. https://doi.org/10.1080/14606925.2015.1059609

Siebe, A. (2018), Die Zukunft vorausdenken und gestalten - Stärkung der Strategiekompetenz im Spitzencluster it's OWL; Springer; Berlin. https://doi.org/10.1007/978-3-662-56264-2

Singh, S. (2012), New Mega Trends: Implications for our Future Lives; Palgrave Macmillan, London. https://doi.org/10.1057/9781137008091

Wübbenhorst, K., Horn, G. A. and Kamps, U. (2018), Gabler Wirtschaftslexikon, available at: https://wirtschaft slexikon.gabler.de/definition/prognose-43498/version-266827 (26.11.2018) 